\title{
Application analysis on the heat recovery technology of heat pump in energy saving of air conditioning in the severe cold regions
}

\author{
Aoxue Chen ${ }^{1,}$, Zhao Chen ${ }^{1, b}$, Chunyu Ran ${ }^{1, c}$ and Chunqing Wang ${ }^{1, d}$ \\ ${ }^{1}$ School of Municipal \& Environmental Engineering,Jilin Jianzhu University,Changchun, P.R.China

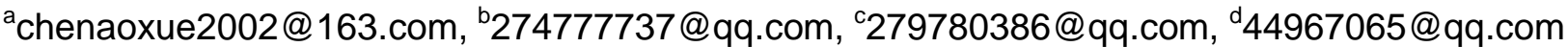

\begin{abstract}
Keywords: the severe cold regions; heat recovery;the recovery fresh air heat pump units;regression analysis.

Abstract. This article introduces the heat recovery technology of heat pump,the recovery fresh air heat pump units which combined the heat pump units and fresh air units, and used heat pump to realize heating recovery from inside building.Heat recovery performance has been tested.By using the principle of regression analysis of mathematical statistics, the article measured data for statistical analysis. The regression equation is established.
\end{abstract}

\section{Introduction}

In the severe cold regions of China, the air-conditioning system in existing buildings is the major energy consuming, carrying out energy saving research and transformation is to be imperative.According to the "public building energy efficiency design standard" [1], it recommends to use the exhaust heat recovery unit in the appropriate conditional case. In order to ensure the indoor air quality, air conditioning system will introduce a large number of fresh air,the majority of indoor air will be discharged, it will take a lot of energy, therefore,the study of exhaust air heat recovery in air conditioning system has a significant meaning for energy saving of air conditioning system.Concerning to study on exhaust air heat recovery technology, Wu Yiping of University of South China[2], they proposed to analyze the energy-saving of air source heat pump based on exhaust air of air-conditioning system. They obtained that it can greatly improve the performance parameters of air source heat pump when they considered the exhaust air of air conditioning system as the low temperature heat source, and analyze its energy saving.College of civil engineering, Hunan University, Yang Guang, Tang Guangfa, Guo Yanjie, Liu Di, Lu Jilong [3], they study the feasibility of small heat recovery device, through recovery the waste heat to preheating or precooling the fresh air which introduced air conditioning system. This method can reduce the energy consumption of air conditioning system.Analyze the principle and performance characteristics of different devices and application characteristics, a preliminary discussion on the rationality of heat recovery equipment configuration and illustrate its energy saving effect, which demonstrates the feasibility of the technology application.Presents the calculation method of a simple economy analysis, and evaluates the economic effect, it demonstrates the economic feasibility.It draws a feasible conclusion about making a small heat recovery device for HVAC system, and prospects the future optimistic.University of South China Yang Chang[4] through the comparison of exhaust air energy recovery technology and economic plan of animal clean room, heat recovery of air source heat pump is relatively less, but the initial investment is little, no additional energy consumption, the investment recovery period is short, it can look as the best heat recovery scheme.In 2007 and 2008, lotus of air conditioning (Jiangsu) Co., Ltd. respectively applied for two patents, using direct expansion heat exchanger to realize heat recovery, it uses exhaust air from indoor as heat transfer medium of heat pump heat exchanger.

Considering the characteristics of climate in severe cold regions in winter, the use of air source heat pump and fresh air units in cold regions is restricted. Due to the too low outdoor temperature, heat capacity of air source heat pump system will be unable to meet the needs of heating in winter in these areas, it needs to add auxiliary heat source, consequently it increases the running cost of the equipment.In addition, the existing defrost criterion of heat pump system can not adapt to the northern wide range of operating conditions, heat pump system false defrosting phenomenon is 
serious, the defrosting time is too long, it leads to fluctuation of the indoor temperature, the user has the obvious blow cold feeling. At the same time, fresh air unit heating coil often burst, causing damage to units and water leakage, resulting in critical economic losses. This article will introduce the recovery fresh air heat pump units, and compared with the traditional air units, it was analyzed based on the measured data, summarizes the technical parameters for guiding practical engineering application, and provides the optimized scheme.

\section{Operation principle of recovery fresh air heat pump units}

The recovery fresh air heat pump units combined the heat pump units and fresh air units, it uses heat pump to realize heating recovery from inside building. Evaporator of heat pump unit is placed in the exhaust pipe in heating recovery system of exhaust energy, and composed the exhaust channel system with exhaust fan.Condenser of heat pump unit is placed in the fresh air pipeline, and composed the fresh air unit and ventilation channel system. In winter, when the outdoor temperature is lower, it needs to improve outdoor low-temperature to high temperature. At this time, heat exchanger in the fresh air channel is condenser, heat exchanger in air exhaust channel side is evaporator, heat pump units work in heating cycle operation, it exchanges heating between the outdoor air and condenser through driven the fresh air unit, and processes to the high temperature state, then supplies to the air conditioning room. The exhaust air in air conditioning room exchanges heating between evaporator and exhaust air through driven the exhaust air fan then outside. Considering the required air volume of heat exchange, the system needs to mix exhaust air with part of outdoor air,which controlling with wind linkage control valve. The system recover heating from indoor air fully, it can realize the function of heat recovery. Evaporator in exhaust channel recycles exhaust air to preheat fresh air, the air temperature reached 5 degrees or 5 degrees above, in order to ensure the freezing temperature requirements of heater coil of fresh air unit in winter, solve the problem of condensation and frosting, defrosting of the air source heat pump system. Corresponding to air handling units of the traditional air conditioning system,recovery fresh air heat pump unis increase the exhaust pipe and heat pump system on the basis of the original system. Traditional air conditioning system disperse exhaust air, when applies heat recovery system, the system must increase the concentration of exhaust pipe, in order to make the exhaust through the evaporator, recover the heating to preheat fresh air.

\section{Analysis of experimental results}

In this paper, with the experimental chamber as the research object, study on the recovery fresh air heat pump units for recovering exhaust air energy to preheat fresh air, measures the indoor and outdoor temperature, supply air temperature, exhaust air temperature, heat pump power consumption parameters, discussed exhaust heat recovery can be improved degree of outdoor air temperature. The temperature changes of recovery fresh air heat pump units during operation is shown in figure 1 . The figure is the indoor and outdoor temperature variation of the recovery fresh air heat pump units in the heating period. As can be seen from the graph, during the operation stage, the outdoor temperature change from $-25 \sim 10^{\circ} \mathrm{C}$, the average is $-15.7^{\circ} \mathrm{C}$, it is mean that system which recovery the exhaust energy can preheat the fresh air above $10^{\circ} \mathrm{C} \mathrm{C}$ the temperature of the fresh air after preheating can reach an average of $14.56^{\circ} \mathrm{C}$, the highest can reach $19.66^{\circ} \mathrm{C}$, it means that exhaust heating recovery can be preheated outdoor air to $10^{\circ} \mathrm{C}$,it meets the demand of the requirements which preheat fresh air $5^{\circ} \mathrm{C}$ or above $5^{\circ} \mathrm{C}$. Therefore, it effectively solves the problem which fresh air units can not work well in cold and serious regions, and extends fresh air unit operation time.

The higher preheating temperature of fresh air, the more heating recovery of the recovery fresh air heat pump units.The heating load in winter which air conditioning unit needs is reduced accordingly, this system can reduce the large demand for heating load in winter. Heating capacity of recovery fresh air heat pump in testing period is shown in Figure 2, the average of heating capacity reaches to $4.72 \mathrm{~kW}$, up to $4.95 \mathrm{~kW}$. Compares the heating load of recovery fresh air heat pump with original air conditioning system in testing period is shown in Figure 3, it can be seen from the figure, 
after using the exhaust heat recovery system, heating load which needed in winter decreased significantly, the heating recovery is very impressive.

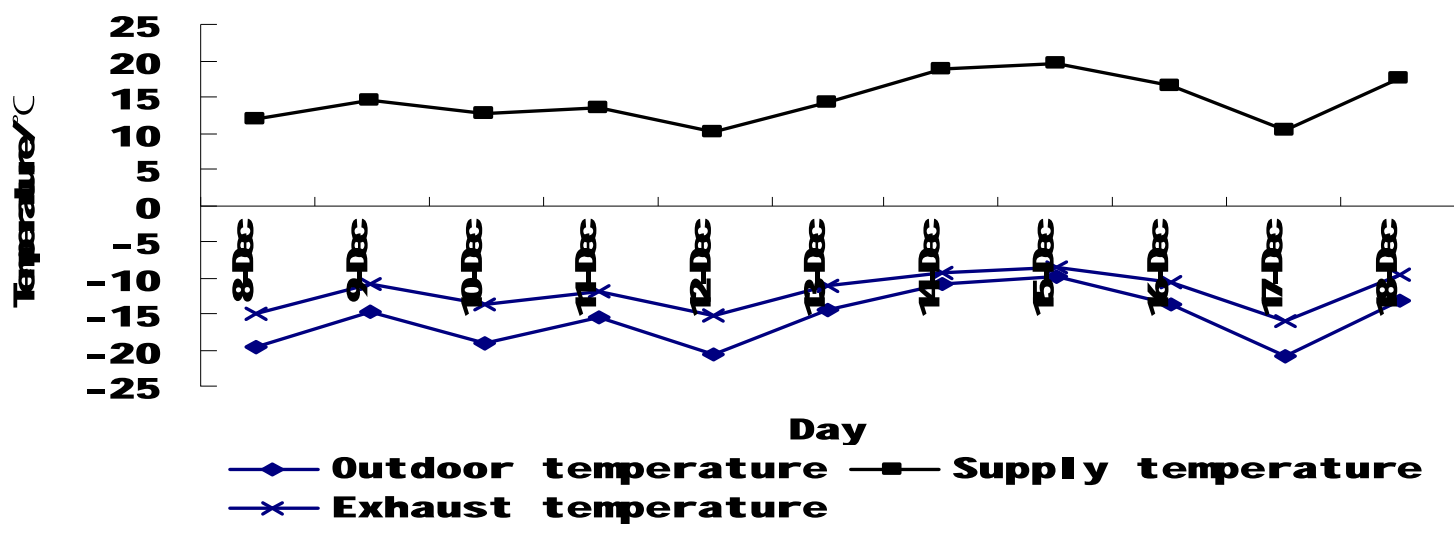

Fig.1. Temperature change in testing period

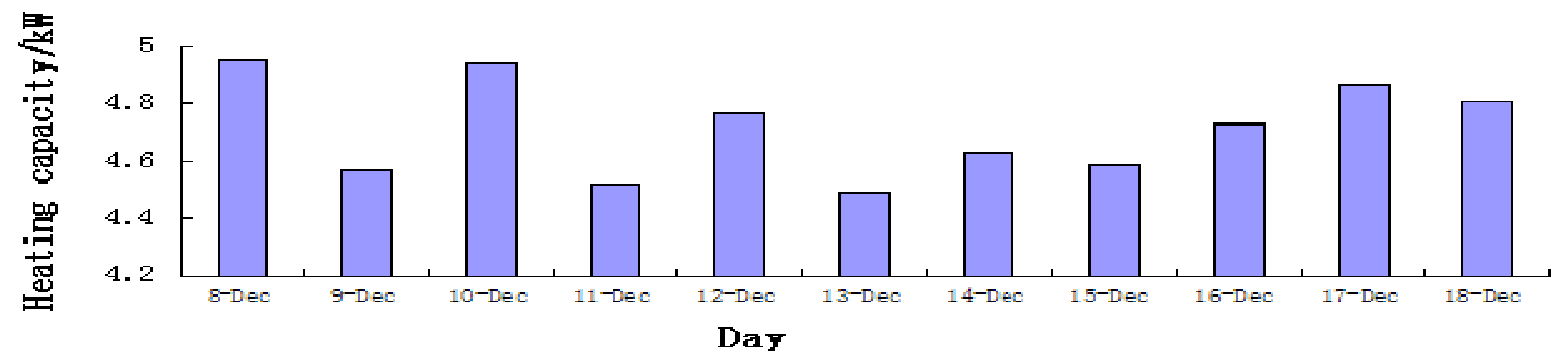

Fig. 2. Heating capacity of recovery fresh air heat pump in testing period

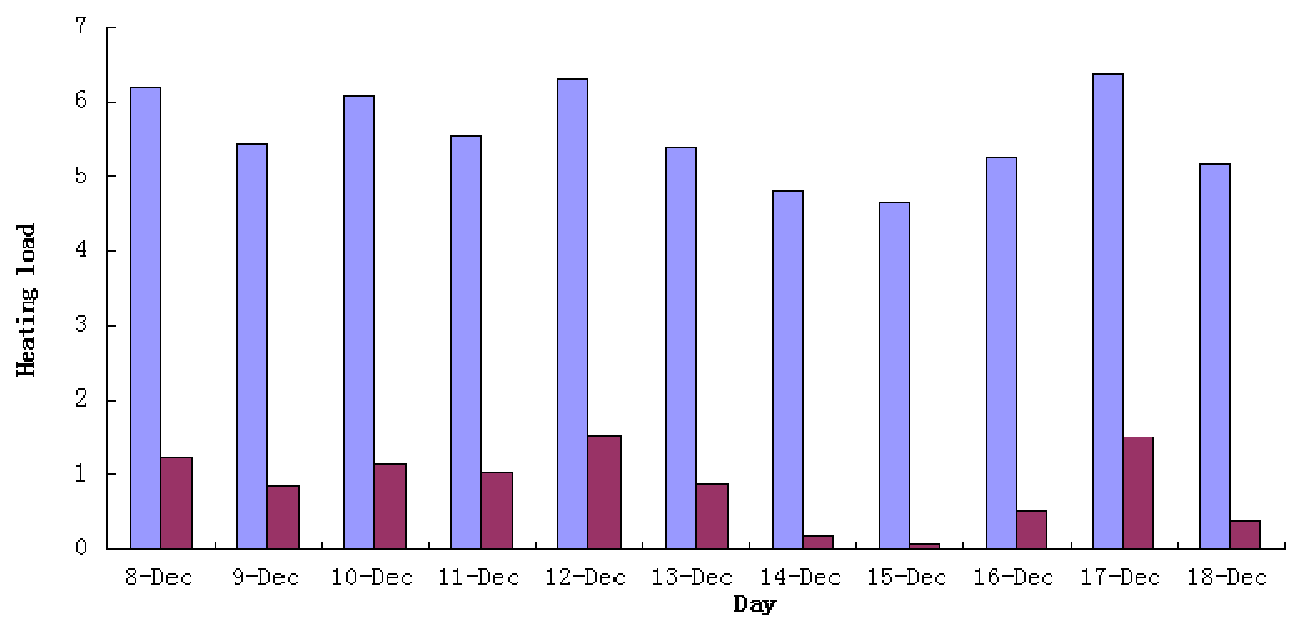

$\square$ Heating load of original air conditioning system $\square$ Heating load of recovery exhaust heating system

Fig.3. Heating load of recovery fresh air heat pump in testing period and original air conditioning system

\section{Regression analysis model}

According to the operation principle of recovery fresh air heat pump units, system recycles exhaust air heating to preheat the outdoor air, it can find the relationship between exhaust air temperature and 
preheating temperature, use the regression analysis theory of mathematical statistics to find out the relationship between the two temperature, summarize the technical parameters for the practical engineering application, provides reference for the related engineering application.

The basic principle of regression analysis. Regression analysis is the most commonly using statistical methods, which handles the relationship between variables. Regression analysis determines the causal relationship of variables through regulates the dependent variables and independent variables, establishes the regression model, and views the regression equation as the method of predictive model. Solve the model of each parameter according to the measured data, and then evaluates the regression model that is able to fit the measured data very well. If it fits finely, it can predict further which bases on independent variables. On the basis of relevant relations between variables and the different number of independent variables, the regression analysis method can be divided into linear regression, multiple linear regression and nonlinear regression.

Test of regression equation. In order to test the predicting effect which regression equation predicts the variables, after the establishment of the regression model,the model is needed for a significance test to confirm the mathematical model which established whether fitting the original data. The significance test of regression model is usually adopted test method of fitting degree. A good equation should be better fit the sample observations. There are three important indexes to determine linear regression fitting,multiple correlation coefficient R,determination coefficient,determination coefficient after the adjustment. Multiple correlation coefficient $\mathrm{R}=$, it describes the correlation between the observed value and estimation value. The determination coefficient is regression sum of squares in the ratio of the total sum of squares of deviations, The higher is, the greater linear regression effect is. It can observe and predict the optimal fitting degree of the model through draw scatter diagram of regression prediction value and statistical value.

Prediction equation fitting scatter diagram of exhaust air temperature and outdoor air temperature is shown in figure 4.The middle curve equation expression is, .The more scatter located in curve, the higher fitting degree of model is.

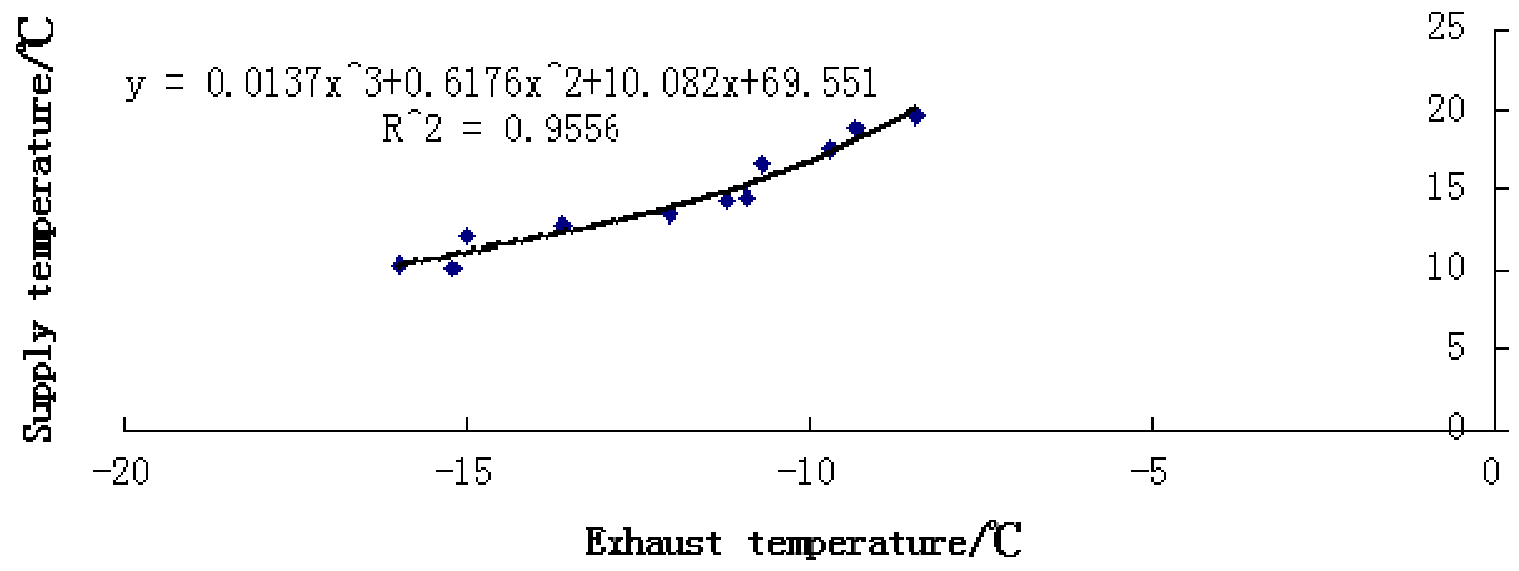

Fig.4. Prediction equation fitting scatter diagram of temperature

Prediction equation fitting scatter diagram of heating load of original air conditioning and the recovery fresh air heat pump unit is shown in figure 5. Oblique line equation graphs above is the relationship between the original air conditioning heating load and the outdoor temperature, through the linear fitting, the expression is. The graph below the diagonal linear equations is the relationship between the air conditioning heating load and outdoor temperature in winter after using the recovery fresh air heat pump units, linear expression is. 


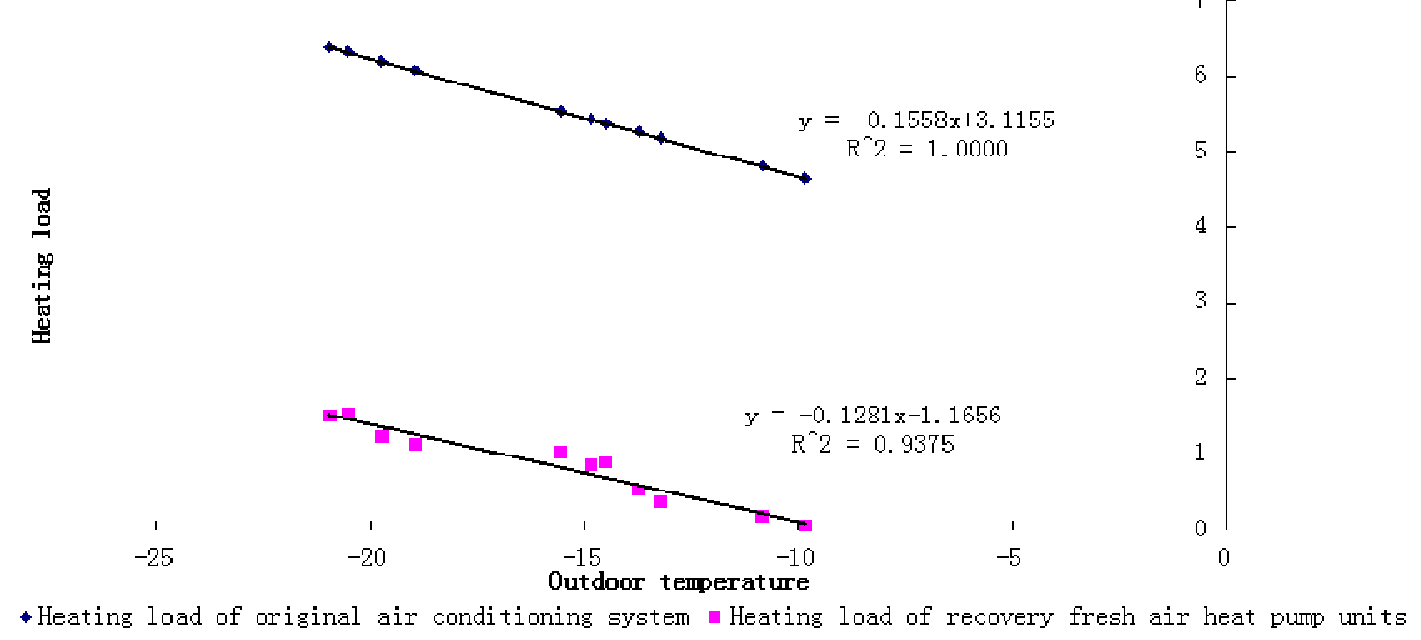

Fig.5. Prediction equation fitting scatter diagram of heating load

From the figure it can be seen, the most points of fitting scattered point diagram is located on a curve. In addition, the of prediction equations is drawn on the upper left corner, it can be found that the decision coefficient have reached more than 0.9. In the general engineering applications, the correlation coefficient $\mathrm{R}$ between the predicted and actual value which reached 0.75 or more is effective forecast, it has the guidance meaning on control strategy. The correlation coefficient which reached 0.85 above has predicted with high precision, so that the regression model in this paper has great prediction accuracy, the model has been tested.

\section{Conclusions}

With carrying on the measured study to the recovery fresh air heat pump units, the system operation characteristics and the actual operating results have been primarily mastered. By analyzing the operation results of the system:

1)During the operation stage, the supply air temperature and indoor temperature is stable and the fluctuation is small. The supply temperature can reach $10^{\circ} \mathrm{C}$ above, which means that system which recovers the exhaust energy can preheat the fresh air more than 10 degree.It meets the demand of the requirements. The average heating capacity of recovery fresh air heat pump in testing period reaches to $4.72 \mathrm{~kW}$, up to $4.95 \mathrm{~kW}$. The heating recovery is very impressive.

2)The measured data with the regression analysis of mathematical statistics method to find out the relationship between the temperature of the exhaust air and preheating air, the regression equation is established,the equation is, the decision coefficient is 0.95566.Linear regression analysis of the heating load of original air conditioning system and using the recovery fresh air heat pump unit is respectively connected with the outdoor temperature, the expression are and.The prediction model accuracy is very high, and provides significant reference for practical engineering application.

\section{Acknowledgements}

This work was financially supported by science and technology research projects of the Education Department of Jilin Province.Research on the recovery fresh air heat pump units in the air conditioning energy saving reform of existing public building in the serious cold regions, thanks to technology and financial support of Education Department of Jilin Province.

The project also has been supported by science and technology development project funding for ministry of housing and urban-rural development of the people/s republic of China.The manufacture of recovery fresh air heat pump unit suitable for severe regions. project Numbers: NO. 2010-k1-45, thanks to technology and financial support of ministry of housing and urban-rural development of the people/s republic of China. 


\section{References}

[1] Chinese Academy of Building Research,Building Energy Professional Committee of Chinese Construction Industry Association.GB50189-2005.Public building energy efficiency design standard[S].Beijing:Chinese Building Industry Press,(2005)

[2] Yiping Wu, Yongjun Ye,Guangxiao Kou, “Analysis on energy saving performance of air source heat pump based on exhaust air" , Proceedings of the Refrigeration air conditioning and power machinery[J], vol.5,May,(2004) p. 26-28.

[3] Yang Guang, Guangfa Tang,Guoyan Jie,Di Liu,Jilong Lu, "The feasibility study of small heat recovery device ", Proceedings of Air conditioning heat ventilation building[J], vol.24,March(,2004)p. 56-60.

[4] Chang Yang, Zehua Liu,Lin Lu,Yongming Duan, "Comparison of technology and economy schemes of exhaust air energy recovery in animal clean room" , Proceedings of HVAC[J], vol.35,June,(2005)p. 79-81. 